\title{
CARACTERÍSTICAS FISIOLÓGICAS DE CULTIVARES DE MORANGUEIRO EM AMBIENTE PROTEGIDO EM CASSILÂNDIA / MS
}

\author{
Thiago Leonel de Assis ${ }^{1}$, Regina Célia Faria Simão Canesin ${ }^{2}$
}

\footnotetext{
${ }^{1}$ Engenheiro Agrônomo - Universidade Estadual de Mato Grosso do Sul, Cassilândia (MS).

${ }^{2}$ Docente do Departamento de Fitotecnia, Tecnologia de Alimentos e Sócio Economia - FE / UNESP Campus de Ilha Solteira (SP).
}

RESUMO: A temperatura e o fotoperíodo influenciam inúmeros processos fisiológicos do morangueiro. Neste contexto o objetivo deste trabalho foi avaliar o comportamento de morangueiros produzidos em ambiente protegido em Cassilândia/MS. O experimento foi conduzido no período de 04/08 à 20/10 de 2010, em ambiente protegido por sombrite na Universidade Estadual de Mato Grosso do Sul em Cassilândia/MS, localizada a $19^{\circ} 05,514^{\prime} \mathrm{S} ; 51^{\circ} 48,900^{\prime} \mathrm{W}$ e altitude de $557 \mathrm{~m}$. Utilizaram-se mudas das cultivares IAC Campinas e Oso Grande conduzidas em canteiros cobertos por mulching de bagaço de cana. Adotou-se o delineamento experimental em blocos casualizados, com 2 tratamentos e 16 repetições e para comparação de médias o teste de Tukey 5\%. Avaliou-se: o início de florescimento; número de flores e de estolhos produzidos por planta; comprimento e diâmetro do morango; massa fresca do morango; número de morangos por planta. Concluiuse que o início de florescimento e colheita do morango para as cultivares IAC Campinas e Oso Grande conduzidas em ambiente protegido no inverno-primavera em Cassilândia/MS não foi alterado pelo ambiente de cultivo, o florescimento teve início aos 21 dias e a colheita aos 40 dias após o transplante das mudas. As características físicas dos morangos não foram alteradas pelo ambiente de cultivo, produziram-se morangos dentro dos padrões descritos para as cultivares. A emissão de estolhos juntamente com florescimento contribuiu para a redução do número de flores e, consequentemente, resultando na menor produção de morangos por planta, em razão disso recomenda-se que sejam realizados experimentos em diferentes épocas de plantio empregando diferentes cultivares.

Palavras-chave: Fragaria x ananassa. Ambiente protegido. Fotoperíodo. Temperatura.

\section{PHYSIOLOGICAL CHARACTERISTICS STRAWBERRY CULTIVARS IN PROTECTED ENVIRONMENT IN CASSILANDIA / MS}

\begin{abstract}
The temperature and photoperiod influence numerous physiological processes in strawberry. In this context the aim of this study was to evaluate the behavior of strawberry cultivars in protected environment. The experiment was conducted in the period 08/04 to 10/20/2010 in protected environment with shading screen at the State University of Mato Grosso do Sul in Cassilândia/MS, located $19^{\circ} 05,514^{\prime} \mathrm{S} ; 51^{\circ} 48,900^{\prime} \mathrm{W}$ and altitude of $557 \mathrm{~m}$. It was used cultivars, IAC Campinas and Oso Grande, conducted in beds mulching covered by sugar cane bagasse. The experimental design was randomized block design with 2 treatments, with 16 replicates and to compare the means used the Tukey rest at 5\%. It was
\end{abstract}

Cultura Agronômica, Ilha Solteira, v.24, n.3, p.235-244, 2015 
evaluated the early flowering; number of flowers and stolons produced per plant; length and diameter of the strawberry; fresh mass of strawberry and number of strawberries per plant. It can be concluded that the early flowering and harvest strawberries for IAC Campinas and Oso Grande conducted in protected environment in winter-spring in Cassilândia/MS was not changed by the cultivation environment, the flowering beginning at 21 days and harvest at 40 days after transplanting; The physical characteristics of strawberries were not changed by the cultivation environment, strawberries were produced within the standards described for cultivars; The issuance of stolons along the flowering contributed to reducing the number of flowers and consequently the plants tended to produce less fruit, because of this it is recommended that experiments are carried out at different planting dates using different cultivars.

Key words: Fragaria x ananassa. Protected environment. Photoperiod. Temperature.

\section{INTRODUÇÃO}

A produção de morangos pela América do Sul é estimada em $318.686 \mathrm{t}$ de frutos de morangos, sendo o Brasil, Argentina e Chile os responsáveis pela maior parte da produção (ANTUNES et al., 2013). No Brasil as regiões Sudeste e Sul merecem maior destaque por corresponder à maior parte das plantações do país. Minas Gerais é o maior produtor com $55 \%$ da produção, seguido por SP com $30 \%$ e RS com 15\%. A produção brasileira se destaca em seis estados como MG (1.200 ha), SP (980 ha), RS (800 ha), PR (270 ha), ES (150 ha), DF (100 ha) e SC (100 ha) que juntos mobilizaram cerca de 4 mil ha, fragmentados na maioria em pequenas propriedades rurais familiares, além desses estados, há cultivo no RJ, BA, CE e AM. As propriedades que se dedicam ao cultivo do morango no país têm como área média cultivada de 0,5 a 1 hectare. Porém podem ser verificados áreas maiores a 15 ha, pertencentes à grandes empresas.

O morangueiro (Fragaria x ananassa) é influenciado por fatores climáticos como temperatura e fotoperíodo. A formação de estolhos é favorecida por dias longos e temperatura elevada enquanto que a indução floral ocorre com temperatura baixa e dias curtos (HOFFMANN; BERNARDI, 2006).

A temperatura influência no crescimento vegetativo, na produção e na qualidade do morango, sendo o principal fator limitante à cultura. Segundo Ronque (1998), a temperatura anual média apropriada para o morangueiro é de 18,5 a $23,8^{\circ} \mathrm{C}$, máxima $32^{\circ} \mathrm{C}$ e mínima $11,4^{\circ} \mathrm{C}$.

A planta exige termoperiodicidade diária, com temperatura diurna amena e noturna mais baixa. Sob temperatura elevada, o morango torna-se excessivamente ácido, pobre em sabor e em aroma e de menor consistência (FILGUEIRA, 2002).

Em regiões de clima temperado, onde as condições de temperatura e fotoperíodo são adequadas ao cultivo do morangueiro, os frutos apresentam melhor sabor, mais adocicados, firmes e com aroma agradável (KOHLER, 2010).

Cultura Agronômica, Ilha Solteira, v.24, n.3, p.235-244, 2015 
No entanto, com o melhoramento genético tem-se desenvolvido cultivares menos exigentes em frio do que as cultivares européias e mais adaptadas às temperaturas amenas, porém elas são igualmente sensíveis ao fotoperíodo. Resultantes desse melhorando são as cultivares paulistas com destaque para a 'IAC Campinas' que tem se adaptado ao cultivo nas mais diversas condições agroecológicas (FILGUEIRA, 2002).

Com a introdução dessas cultivares o cultivo do morango já é realidade em várias regiões de clima mais quente como centro oeste por exemplo. Marchese et al. (2006) avaliando as respostas fisiológicas às condições de termofotoperiódicas de cultivares de morango observaram que para as condições climáticas do centro-oeste, a cultivar Sweet Charlie se destacou das cultivares Campdover, Toynoka, Oso grande, Diamante, Campinas, Tudla, Camarosa para a produção de flores sendo a mais recomendada para cultivo no outono/inverno e na primavera. No verão recomendam a cultivar Diamante devido sua efetividade para a emissão de flores em relação as demais cultivares.

Pallamin et al. (2004) após a avaliação da produção de morangos em regiões mais quentes recomendam as cultivares Oso Grande, Dover, Sweet Charlie e Camarosa para o cultivo na região de Bauru/SP ou regiões com condições edafoclimáticas semelhantes.

$\mathrm{O}$ morangueiro pode ser cultivado à campo ou em ambiente protegido. $\mathrm{O}$ cultivo em ambiente protegido visa proteger a cultura das baixas temperaturas, diminuindo com isso a incidência de doenças foliares e de podridões dos frutos, proporcionando ainda uma série de vantagens, como proteção da cultura contra ventos, granizo, chuvas, geadas e ataque de pragas e doenças, além de favorecer a precocidade de cultivares como Campinas e a produção de frutos de melhor qualidade (CALVETE et al., 2008).

A cobertura do solo na cultura do morangueiro é outra prática utilizada principalmente na produção de frutos. A utilização de cobertura evita o contato do fruto com o solo; influencia na manutenção da temperatura do solo, atuando como termorregulador; evita a compactação do solo principalmente quando usada a irrigação por aspersão; tem ainda ação sobre as plantas invasoras. O material mais utilizado na cobertura do solo é o plástico preto com espessura de 30 micras. Porém outros materiais também podem ser utilizados como a palha de arroz; trigo, centeio, cevada, folhas de árvores, serragem, biruta ou maravalha de madeira, colmos picados de milho, sorgo, milheto, cana-de-açúcar, bagaço de cana-deaçúcar, etc. (MEDEIROS; SANTOS, 2005; PASSOS et al., 1998).

Neste contexto o objetivo deste trabalho foi avaliar o comportamento de morangueiros produzidos em ambiente protegido em Cassilândia/MS.

\section{MATERIAL E MÉTODOS}

O experimento foi conduzido no período de 04/08 à 20/10 de 2010 em ambiente protegido por sombrite $70 \%$ em uma área experimental da Universidade Estadual de Mato Grosso do Sul em Cassilândia-MS, localizada a 1905,514'S; 5148,900'W e altitude de 557m (GPS Garmin nuvi 250).

Cultura Agronômica, Ilha Solteira, v.24, n.3, p.235-244, 2015 
O clima da região, segundo a classificação de Koppen é considerado tropical chuvoso (Aw), com verão chuvoso e inverno seco, apresentando precipitação média anual no período de inverno de 26,4 mm e fotoperíodo médio para os meses de agosto e setembro de 11,3 e 11,9 horas de luz, respectivamente (PEREIRA et al., 2002).

No período de condução do experimento foram coletados dados climatológicos cuja precipitação acumulada e temperaturas mínima, média e máxima estão descritas na Tabela 1 .

Tabela 1. Dados climatológicos das médias de temperatura $\left({ }^{\circ} \mathrm{C}\right)$ mínima, máxima, média e precipitação $(\mathrm{mm})$ observados para Cassilândia/MS, nos meses de agosto à outubro de 2010.

\begin{tabular}{ccccc}
\hline Mês & $\begin{array}{c}\text { Temp. média } \\
\text { mínima } \\
\left({ }^{\circ} \mathrm{C}\right)\end{array}$ & $\begin{array}{c}\text { Temp. média } \\
\text { máxima } \\
\left({ }^{\circ} \mathrm{C}\right)\end{array}$ & $\begin{array}{c}\text { Temp. média } \\
\left({ }^{\circ} \mathrm{C}\right)\end{array}$ & $\begin{array}{c}\text { Precipitação } \\
\text { acumulada } \\
(\mathrm{mm})\end{array}$ \\
\hline Agosto & 12,8 & 31,9 & 22,35 & 0,3 \\
Setembro & 19,0 & 33,8 & 26,4 & 14,0 \\
Outubro & 19,7 & 32,7 & 26,2 & 113,6 \\
\hline
\end{tabular}

Fonte: JORNAL DO TEMPO (2010).

As mudas utilizadas no experimento foram obtidas do Núcleo de produção de mudas da Coordenadoria de Assistência Técnica Integral-CATI, localizado em São Bento do Sapucaí-SP. Foram utilizadas mudas com raízes nuas e com 3 meses de idade das cultivares Oso Grande e IAC Campinas.

A cultivar Campinas (IAC-2712) desenvolvida pelo Instituto Agronômico-IAC, é uma cultivar de dias curtos, rústica; fruto grande e doce; boa para mesa e boa produtividade. Apresenta pouca exigência em frio, sendo por isso especialmente indicada para plantios visando colheita precoce (KOHLER, 2010; SANTOS, 2005).

A cultivar Oso Grande desenvolvida pela Universidade da Califórnia-EUA é uma cultivar de dias curtos e de grande adaptabilidade; planta vigorosa, com folhas grandes e de coloração verde escura; ciclo mediano e elevada capacidade produtiva. Frutos de tamanho grande, polpa de textura firme no início da produção e mediana no final da colheita, de coloração vermelha clara e aromática; epiderme vermelha clara; sabor subácido, próprio para consumo "in natura" (KOHLER, 2010; SANTOS, 2005).

As mudas foram transplantadas para os canteiros em 04 de agosto de 2010, selecionando as mais uniformes em tamanho, no espaçamento de $25 \times 30 \mathrm{~cm}$ conforme recomendado por Filgueira (2002).

Os canteiros foram preparados com $5 \mathrm{~m}$ de comprimento $\mathrm{x} 1 \mathrm{~m}$ de largura $\mathrm{x}$ 0,20 $\mathrm{m}$ de altura, com volume de $1 \mathrm{~m}^{3}$ cada, constituídos de solo retirado da área experimental e previamente adubado conforme análise química de solo (Tabela 2).

Para a adubação dos canteiros utilizou-se $1,2 \mathrm{~kg}$ de calcário; 0,346 kg de cloreto de potássio; 5,0 kg de super simples; 0,2 kg sulfato de amônio e $15 \mathrm{~kg}$ de esterco de curral curtido (RAIJ et al., 1997) e para irrigação o sistema de gotejamento. Após o pegamento das mudas os canteiros foram cobertos utilizando-se um mulching de bagaço de cana triturada. 
Tabela 2. Resultado da análise química do solo da área experimental utilizado para a formação dos canteiros.

\begin{tabular}{ccccccccc}
\hline \multicolumn{7}{c}{ Resultados Analíticos } \\
\hline $\begin{array}{c}\text { P-resina } \\
\mathrm{mg} / \mathrm{dm}^{3}\end{array}$ & $\begin{array}{c}\mathrm{MO} \\
\mathrm{g} / \mathrm{dm}^{3}\end{array}$ & $\begin{array}{c}\mathrm{pH} \\
\mathrm{CaCl}_{2}\end{array}$ & $\begin{array}{c}\mathrm{K} \\
\mathrm{mmolc} / \mathrm{dm}^{3}\end{array}$ & $\begin{array}{c}\mathrm{Ca} \\
\mathrm{mmolc} / \mathrm{dm}^{3}\end{array}$ & $\begin{array}{c}\mathrm{Mg} \\
\mathrm{mmolc} / \mathrm{dm}^{3}\end{array}$ & $\begin{array}{c}\mathrm{H}+\mathrm{Al} \\
\mathrm{mmolc} / \mathrm{dm}^{3}\end{array}$ & $\begin{array}{c}\mathrm{Al} \\
\mathrm{mmolc} / \mathrm{dm}^{3}\end{array}$ & $\begin{array}{c}\mathrm{SB} \\
\mathrm{mmolc} / \mathrm{dm}^{3} \\
4\end{array}$ \\
22 & 4,8 & 4,3 & 7 & 9 & 28 & 3 & 20,3 \\
\hline $\mathrm{S}^{-\mathrm{SO}_{4}}$ & $\mathrm{CTC}$ & $\mathrm{V}$ & $\mathrm{M}$ & $\mathrm{B}$ & $\mathrm{Cu}$ & $\mathrm{Fe}$ & $\mathrm{Mn}$ & $\mathrm{Zn}$ \\
$\mathrm{mg} / \mathrm{dm}^{3}$ & $\mathrm{mmolc} / \mathrm{dm}^{3}$ & $\%$ & $\%$ & $\mathrm{mg} / \mathrm{dm}^{3}$ & $\mathrm{mg} / \mathrm{dm}^{3}$ & $\mathrm{mg} / \mathrm{dm}^{3}$ & $\mathrm{mg} / \mathrm{dm}^{3}$ & $\mathrm{mg} / \mathrm{dm}^{3}$ \\
2 & 48,3 & 42 & 13 & 0,09 & 0,7 & 19 & 5,7 & 0,3 \\
\hline
\end{tabular}

Fonte: Laboratório de Fertilidade de solo da FEIS-UNESP.

Em 25 de agosto de 2013, ou seja, aos 21 dias após o transplantio (DAT) as plantas iniciaram o florescimento, ocasião em que foram marcadas e realizada semanalmente uma contagem do número de flores emitidas por planta. Em 15 de setembro de 2013, quando as mudas iniciaram a emissão de estolhos foi realizada semanalmente a contagem do número de estolhos emitidos por planta.

Em 15 de setembro de 2013 (40 DAT), quando os morangos atingiram 75\% da superfície de coloração vermelha, conforme recomendado por Filgueira (2002), foi realizada a colheita e avaliação da massa fresca, comprimento e diâmetro final dos morangos, bem como contagem do número de morangos produzidos por planta.

Os morangos colhidos foram levados para o laboratório, onde foram pesados em uma balança digital, para obtenção da massa fresca e onde foi realizada a medida, com paquímetro o comprimento e diâmetro dos morangos.

O delineamento experimental adotado foi de blocos casualizados, com 2 tratamentos e 16 repetições e para comparação de médias utilizou-se o teste de Tukey a 5\% de probabilidade conforme metodologias descritas por Banzatto e Kronka (1995).

\section{RESULTADOS E DISCUSSÃO}

Aos 21 DAT observou-se o início do florescimento para as cvs. Oso Grando e IAC Campinas e aos 40 DAT início da emissão de estolhos, concordando com o relatado por Hoffmann e Bernardi (2006) e Filgueira (2002). Segundo os autores a formação de estolhos é favorecida por dias longos e temperatura elevada corroborando com essas condições verifica-se que com o início da primavera em setembro as temperaturas entre $19,0^{\circ} \mathrm{C}$ a $33,8^{\circ} \mathrm{C}$ e fotoperíodo de 11,3 a 11,9 horas favoreceram a produção de estolhos (Tabela 1).

Vale ressaltar que a emissão de estolhos juntamente ao florescimento contribuiu para a redução do número de flores e consequentemente menor produção de morangos por planta. Contudo foi possível observar que a cultivar IAC Campinas apresenta estatisticamente maior número de flores e maior número de estolhos que a cultivar Oso Grande (Tabela 3), contrário aos resultados obtidos por Marchese et al. (2006) onde a cultivar Oso Grande e IAC Campinas não tiveram diferença estatística para número de flores e número de estolhos, tanto no inverno como na primavera. De acordo com os autores no inverno a 
cultivar Oso Grande produziu 15,5 flores e 6,25 estolhos e a cultivar IAC Campinas produziu 10 flores e 6,05 estolhos, na primavera a cv. Oso grande produziu 13,5 flores e 5 estolhos, e a cv. IAC Campinas produziu 11,75 flores e 8,75 estolhos.

É citado na literatura que a capacidade de maior ou menor produção de estolhos é depende da cultivar e das condições ambientais do local em que as plantas se encontram. Tessarioli Neto et al. (2003) observaram que para as condições climáticas de Piracicaba/SP, as cvs. Dover e Campinas produziram maiores quantidades de mudas em comparação as cvs. IAC Princesa; Isabel; Chandler; Pajaro, Toyonoka e Korona.

Tabela 3. Número de flores e estolhos por planta produzidos no período de agosto à outubro.

\begin{tabular}{ccc}
\hline Cultivares & $\mathrm{N}^{\circ}$ de flores/planta & $\mathrm{N}^{\circ}$ de estolhos/planta \\
\hline IAC Campinas & $4,6 \mathrm{a}^{*}$ & $2,9 \mathrm{a}$ \\
Oso Grande & $4,5 \mathrm{~b}$ & $1,4 \mathrm{~b}$ \\
\hline C.V.** $(\%)$ & 12,5 & 6,5 \\
\hline
\end{tabular}

*médias seguidas de letras minúsculas iguais nas colunas não diferem entre si pelo teste de Tukey a 5\%. ${ }^{* *}$ C.V. $=$ Coeficiente de Variação.

Aos 40 DAT, quando então os morangos atingiram $75 \%$ da superfície vermelha, teve início a colheita, período de tempo menor aos 60 a 80 dias após o plantio das mudas como relatado por Cantillano (2005), mas concordando com Ronque (1998), que de acordo com o autor o morangueiro inicia a produção de 20 a 40 dias após o plantio da muda no campo, produzindo geralmente de forma continua por vários meses.

Observa-se na Tabela 4 que as cultivares diferiram estatisticamente para massa fresca do morango e não apresentaram diferença estatística para o comprimento, diâmetro e número de morangos produzidos por planta, semelhante ao resultado obtido por Pallamin et al. (2004) que verificaram que as cvs. Oso grande e IAC produzidas na região de Bauru/SP não tiveram diferença estatística para produção e número de frutos produzidos por hectare.

A cv. Oso Grande produziu morangos com maior massa fresca em relação à cv. IAC Campinas. A cv. IAC Campinas (Tabela 4) produziu morangos com massa fresca de 7,7 $\mathrm{g}$ com 3,0 cm de comprimento e 2,1 cm de diâmetro, corroborando com as características descritas para essa cultivar.

Em estudo conduzido sob condições climáticas de inverno na estação experimental de Monte Alto do Sul/SP, a cv. IAC Campinas produziu morangos com 7,7 g e na estação experimental de Jundiaí/SP, morangos com 7,4 g (CAMARGO, 1968). Na região de Atibaia/SP a cv. IAC Campinas produziu morangos que variam de 6,12 g (PASSOS et al., 1998) a 9,91 g (CONTI et al. 2002). Conti et al. (2002) também obtiveram morangos dessa cultivar com 8,33 g em Piracicaba/SP.

Verifica-se que a cv. Oso Grande produziu morangos com massa média de 9,3 g com $3,0 \mathrm{~cm}$ de comprimento e $1,88 \mathrm{~cm}$ de diâmetro (Tabela 4), estando os valores de massa fresca dentro das faixas de 8,78 a 10,02 g obtidos por Camargo et al. (2010) e próximos aos obtidos por Calvete et al. (2008) que foi de aproximadamente de 10,0 g. 
Nota-se por meio desses resultados que as cultivares analisadas Oso Grande e IAC Campinas produzidas em ambiente protegido apresentaram valores de massa fresca, comprimento e diâmetro muito semelhantes aos resultados relatados pelos diversos autores, o que evidencia que o ambiente de cultivo não interferiu nas características físicas do morango.

Quanto ao número de morangos produzidos por planta verifica-se que as cultivares produziram em média 3,0 morangos por planta, comparando esse valor aos obtidos por Pereira et al. (2013) e considerando-se que a colheita no experimento citado teve duração de 4 meses, 2 meses a mais que no presente experimento, os resultados encontram-se abaixo daqueles obtidos pelos autores que foram de 16,24 morangos por planta para a cultivar Oso Grande e se aproximam dos 4,4 morangos por planta obtidos pela cultivar Camarosa, outra cultivar também de dias curtos.

Os autores avaliando épocas de plantio para as diversas cvs. de morango em Bom Repouso/MG verificaram que o plantio realizado no mês de agosto a cv. Oso Grande uma cultivar de dias curtos apresentou desempenho semelhante à cultivar Aromas, neutra ao fotoperíodo, o que torna essa cultivar muito interessante para cultivo em diferentes épocas de plantio, fato que foi comprovado por Pereira et al. (2013) quando observaram que independente da época de plantio (maio, junho, julho ou agosto) em Bom Repouso/MG a cultivar Oso Grande foi a que apresentou melhor resultado quando comparada às cultivares Aromas, Camarosa e Festival.

Tabela 4. Massa fresca $(\mathrm{g})$, comprimento $(\mathrm{cm})$, diâmetro $(\mathrm{cm})$ e número de morangos por planta produzidos em ambiente protegido em Cassilândia/MS.

\begin{tabular}{lcccc}
\hline \multicolumn{1}{c}{ Cultivares } & $\begin{array}{c}\text { Massa fresca } \\
(\mathrm{g})\end{array}$ & $\begin{array}{c}\text { Comprimento } \\
(\mathrm{cm})\end{array}$ & $\begin{array}{c}\text { Diâmetro } \\
(\mathrm{cm})\end{array}$ & $\begin{array}{c}\mathrm{N}^{\circ} \text { de } \\
\text { morangos/planta }\end{array}$ \\
\hline IAC Campinas & $7,7 \mathrm{~b}^{*}$ & $3,0 \mathrm{a}$ & $2,1 \mathrm{a}$ & $3,1 \mathrm{a}$ \\
Oso Grande & $9,3 \mathrm{a}$ & $3,1 \mathrm{a}$ & $2,1 \mathrm{a}$ & $3,0 \mathrm{a}$ \\
\hline C.V.** $(\%)$ & 48,3 & 14,3 & 27,3 & 7,7 \\
\hline *médias seguidas de letras minúsculas iguais na coluna não diferem entre si pelo teste de Tukey a 5\%. \\
**.V.= Coeficiente de Variação.
\end{tabular}

\section{CONCLUSÃO}

O início de florescimento e colheita do morango para as cultivares IAC Campinas e Oso Grande conduzidas em ambiente protegido no inverno-primavera em Cassilândia/MS não foi alterado pelo ambiente de cultivo, o florescimento com início aos 21 dias e a colheita aos 40 dias após o transplante das mudas; As características físicas dos morangos não foram alteradas pelo ambiente de cultivo, produziram-se morangos dentro dos padrões descritos para as cultivares; A emissão de estolhos juntamente com o florescimento contribuiu para a redução do número de flores e, consequentemente, resultando na menor produção de morangos por planta, em razão disso recomenda-se que sejam realizados experimentos em diferentes épocas de plantio empregando diferentes cultivares. 


\section{REFERÊNCIAS BIBLIOGRÁFICAS}

ANTUNES, L. E. C.; VIGNOLO, G.; GONÇALVES, M. Morango novas tecnologias incrementam o setor. Anuário HF 2013: Revista Campo \& Negócios. Uberlândia, p.56$59,2013$.

BANZATTO, D. A.; KRONKA, S. N. Experimentação Agrícola. 3. ed. Jaboticabal: FUNEP, 1995. 247 p.

CALVETE, E. O.; MARIANI, F.; WESP, C. L.; NIENOW, A. A.; CASTILHOS, T.; CECCHETTI, D. Fenologia, produção e teor de antocianinas de cultivares de morangueiro em ambiente protegido, Revista Brasileira de Fruticultura, Jaboticabal, v. 30, n. 2, p.396401, 2008.

CAMARGO, L. S. Novos cultivares de morangueiro para região do alto piracicaba no planalto paulista, Bragantia, Campinas, v.27, n. 10, p.117-133, 1968.

CAMARGO, L. K. P.; RESENDE, J. T. V.; GALVÃO, A. G.; CAMARGO, L. K.; BAIER, J. E. Desempenho produtivo e massa média de frutos de morangueiro obtidos de diferentes sistemas de cultivo. Ambiência, Guarapuava, v. 6, n. 2, p.281-288, 2010.

CANTILlANO, R. F. F. Colheita e pós colheita. In: EMBRAPA EMPRESA BRASILEIRA DE PESQUISA AGROPECUÁRIA. Sistemas de produção do morango. $2005 . \quad$ Disponível em: <http://sistemasdeproducao.cnptia.embrapa.br/FontesHTML/Morango/SistemaProducaoMo rango/index.htm>. Acesso em: 30 abr. 2014.

CONTI, J. H.; MINAMI, K.; TAVARES, F. C. A. Produção e qualidade de frutos de morango em ensaios conduzidos em Atibaia e Piracicaba. Horticultura Brasileira, Brasília, v. 20, n. 1, p.10-17, 2002.

FILGUEIRA, F. A. R. Novo manual de olericultura: agrotecnologia moderna na produção e comercialização de hortaliças. Viçosa: UFV, 2002. 402 p.

HOFFMANN, A.; BERNARDI, J. Produção de morango no sistema semi-hidropônico. In: EMBRAPA UVA E VINHO, Sistema de produção. 2006. Disponível em: <http://www.cnpuv.embrapa.br/publica/sprod/MorangoSemiHidroponico/index.htm>. Acesso em: 30 abr. 2014.

JORNAL DO TEMPO. Dados observados para Cassilândia-MS. Disponível em: <http://jornaldotempo.uol.com.br/observados.html/Cassilandia-MS/>. Acesso em: 01 ago. 2010.

Cultura Agronômica, Ilha Solteira, v.24, n.3, p.235-244, 2015 
KOHLER A. Cultivo de Morango. Disponível em: $<$ http://apostilasgratuitas.info/oportunidades-e-negocios/52-oportunidades-e-negocios/405cultivo-de-morango>. Acesso em: 15 jun. 2010.

MARCHESE, A.; RESENDE, J. T. V.; MINTKEWSKI, R.; FARIA, M. V.; NASCIMENTO, I. R.; MARONDIN, J. C.; PIRES, D. B.; KACMARCZYK, P. H. Respostas fisiológicas de cultivares de morango a diferentes regimes de temperatura e fotoperíodo. In: CONGRESSO BRASILEIRO DE OLERICULTURA, 46., 2006, Goiânia. Anais eletrônicos... Goiânia: ABH, 2006. Disponível em: <http://www.abhorticultura.com.br/biblioteca>. Acesso em: 15 jul. 2010.

MEDEIROS, A. R. M.; SANTOS, A. M. Práticas culturais. In: EMBRAPA EMPRESA BRASILEIRA DE PESQUISA AGROPECUÁRIA. Sistemas de produção do morango. 2005.

<http://sistemasdeproducao.cnptia.embrapa.br/FontesHTML/Morango/SistemaProducaoMo rango/index.htm>. Acesso em: 30 abr. 2014.

PALlAMIN, M. L.; SAMPAIO, A. C.; FUMIS, T. F.; OLIVEIRA, M. O. P. Avaliação da produtividade de nove cultivares de morango na região de Bauru - SP. Cultura Agronômica, Ilha Solteira, SP, v.13, n.2, p. 54-67, 2004.

PASSOS, F. A.; TRANI, P. E.; BETTI, J. A.; TANAKA, M. A. S. Morango. In: FAHL, J. I. CAMARGO, M. B. P.; PIZZINATTO, M. A.; BETTI, J. A.; MELO, A. M. T.; DeMARIA, I. C.; FURLANI, A. M. C. Instruções Agrícolas para as principais culturas econômicas. 6. ed. Campinas: IAC, 1998. p. 222-225. (Boletim IAC 200).

PEREIRA, A. R.; ANGELOCCI, L. R.; SENTELHAS, P. C. Agrometeorologia: fundamentos e aplicações. Guaíba: Agropecuária, 2002. 86 p.

PEREIRA W. R; SOUZA, R. J.; YURI, J. E.; FERREIRA, S. Produtividade de cultivares de morangueiro, submetidas a diferentes épocas de plantio. Horticultura Brasileira, Brasília, v. 31, n. 3, p.500-503, 2013.

VAN RAIJ, B. Recomendação de adubação e calagem para o Estado de São Paulo. $2^{a}$ ed. Campinas: Instituto Agronômico/Fundação IAC, 1997. 285 p. (Boletim Técnico, 100).

RONQUE, E. R. V. A cultura do Morangueiro. Curitiba: Emater, 1998. 206 p.

SANTOS, P. E. T. Sistema de Produção de Morango. 2005. Disponível em $<$ http://sistemasdeproducao.cnptia.embrapa.br/FontesHTML/Morango/SistemaProducaoMo rango/cap02.htm>. Acesso em: 30 abr. 2014.

Cultura Agronômica, Ilha Solteira, v.24, n.3, p.235-244, 2015 
TESSARIOLI NETO, J.; ORTIGOZA, L. E. R.; VERDIAL, M. F. Produção de mudas de cultivares de morangueiro em duas épocas de coleta. Horticultura Brasileira, Brasília, v. 21, n. 2, p.231-233, 2003. 